\title{
OPTIMAL CONTROL OF WIND POWER GENERATION
}

\author{
Pawel Pijarski ${ }^{1}$, Michal Wydra ${ }^{1}$, Piotr Kacejko ${ }^{1}$ \\ 1 Lublin University of Technology, Nadbystrzycka 38A, 20-618 Lublin, Poland, e-mail: p.pijarski@pollub.pl, \\ m.wydra@pollub.pl, p.kacejko@pollub.pl
}

Received: 2017.04.15

Accepted: 2018.02.01

Published: 2018.03.01

\begin{abstract}
Power system control is a complex task, which is strongly related to the number and kind of generating units as well as to the applied technologies, such as conventional coal-fired power plants or wind and photovoltaic farms. Fast development of wind generation that is considered as unstable generation sets new strong requirements concerning remote control and data hubs cooperating with SCADA systems. Considering specific nature of the wind power generation, the authors analyze the problem of optimal control for wind power generation in farms located over a selected remotecontrolled part of the System Operator grid under advantageous wind conditions. This article presents an original stepwise method for tracing power flows that makes possible to eliminate current (power) overloading of power grid branches. Its core idea is to consider the discussed problem as an optimization task.
\end{abstract}

Keywords: wind farms; estimation; optimization; SCADA; power generation reduction; overloading;

\section{INTRODUCTION}

The National Power System of Poland is popularly considered to be old, worn-out and noneffective. Many old and non-revitalized power transmission lines of relatively low current ratings do not enable high power transmission. Because of their age of thirty years at the average, they are more susceptible to failures. Ever growing demand for electrical energy imposes modernization of power lines to increase their current ratios. New investments are also necessary. Modernization of transmission lines is very expensive with its costs almost approaching the costs of new installations. Taking the above into account, it seems necessary to find new alternative and cost-effective solutions that could make possible to use the existent infrastructure more efficiently.

One of the possible solutions is to invest in green energy, that is in the renewable energy sources like wind farms or geothermal plants. Actions promoting this solution are indispensable. Poland like other countries is obliged to meet the EU directive requirements for increasing the share of green energy in the power balance of the National Power System. Wind farms (WF) as dispersed generation sources seem to be perfect for meeting the demands of local energy markets as they eliminate the need to build new coal-fired plants and the distribution networks. Control of the WF operation involves a number of problems and makes a demanding task for the grid operators. Owing to their expertise and intuition, proper actions can be taken to prevent such hazards as overloading of transmission lines or voltage surges.

When the wind power generation falls below a specific critical value, the farm is disconnected from the system. On the other hand, at good wind conditions, wind farms can generate too much power to be transmitted through the system, which can cause overloading of the system power lines. When such overloading occurs, the operator can decide to reduce the power generation or to disconnect the source from the grid. A disconnection of a wind farm from the grid results in 
the loss of that green energy. The authors would like emphasize that disconnection of a wind farm to prevent or reduce overloading of a particular power line is not an optimal way to cope with the problem, and that is why an attempt to optimally solve it has been taken.

\section{LOGICAL MODEL}

\section{General concept}

The above mentioned preventive actions of grid operators often involve constraints on the WF generation capacity which is not an optimal solution. In order to take maximum advantage of the wind farm potential, an innovative tool has been developed. The primary objective of this tool is to compute adequate (maximum possible) active power settings for the actual weather and technical conditions. When overloading of power system lines occurs, the tool can prompt a solution, where all of the following conditions are met:

- power balance,

- line load reduction to acceptable limits,

- voltage limits are not exceeded.

Fig. 1 presents a generic algorithm that realizes the above assumptions. This tool works as a closed-loop system and depending on the configuration (and assumptions) it can run entirely autonomously or semi-automatically. In the first case, when all needed data are collected, the system computes the solution and sends new power settings directly to the wind farms. In the other case, the operator approval is required before the computed settings are sent to the wind farm control apparatus.

The discussed optimal regulation algorithm consists of the following stages:

- data (measurements) retrieval from the SCADA system,

- computation of an actual power system model,

- optimization computations,

- update of the wind farm power settings.

This algorithm includes two primary modules that are responsible for the computations: the state estimator and the optimization module. The first one determines an actual model of the power system and the other one uses the optimization algorithm to calculate the best active power settings for the current weather conditions.

\section{State estimator}

The main weakness of real power systems is their lack of full observability. In many areas of a power network, it is only single voltage or power flow measuring devices that are used for the measurement purposes. It also happens that there are areas, where completely no measure-

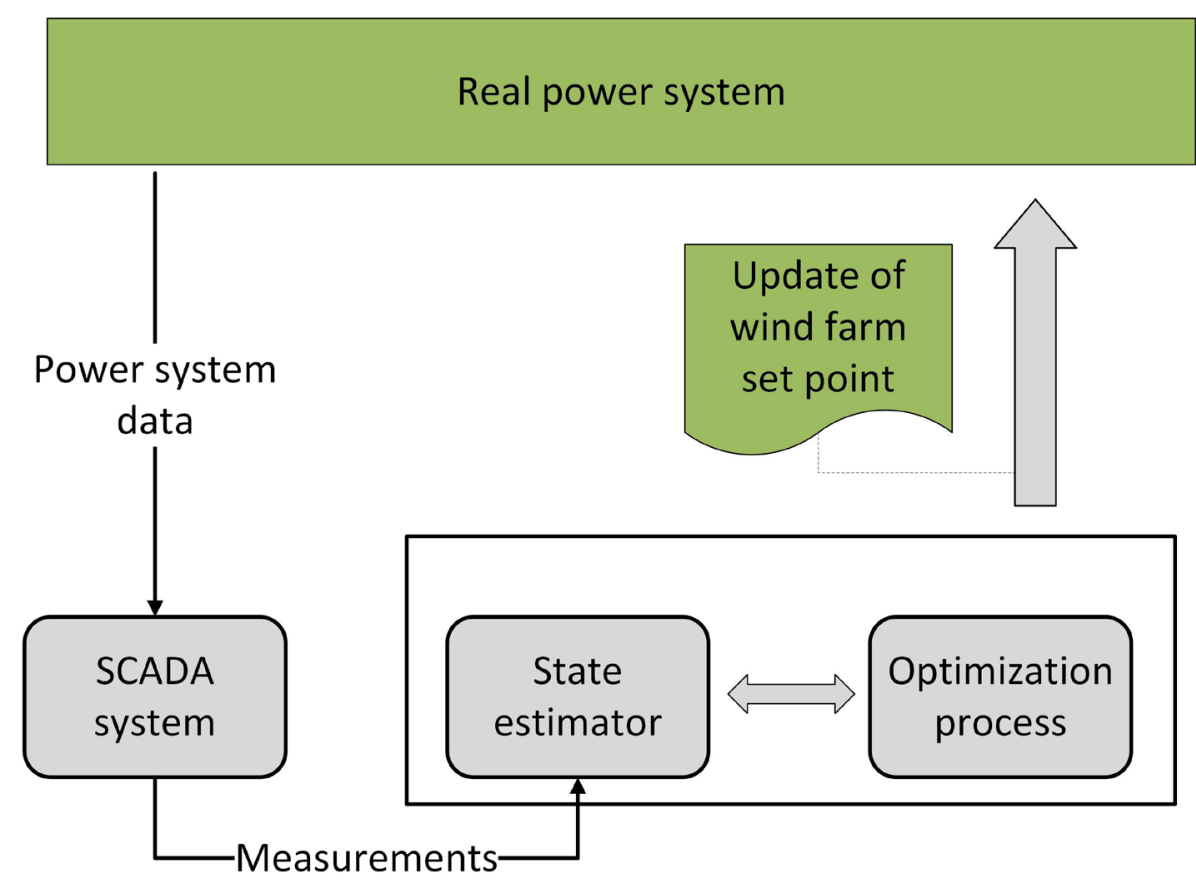

Figure 1 Logical concept of the developed tool 
ments are taken. There can be various reasons for such a situation. In most cases, it follows from economic and technical aspects. Preparation of a measuring device for the operation with an $\mathrm{HV}$ network is more expensive than it is in the case of the MV infrastructure. Such problems considerably influence controllability and stability of power systems. In order to prevent the occurrence of failures and improve the control quality, it is necessary to search for new less expensive and more efficient solutions such as tools included in computer programs. In most cases, those programs are used as applications based on a simplified mathematical model of a power system. They run in offline mode. It is some disadvantage especially in the case of a real-time control of the HV power system. Such simplified models assume that all the needed data about the system topology, impedance, power flow data, voltage are available. Complex connections among the system elements, the questionable condition of switches, incorrect values obtained from analog measurements or unavailability of measurement data make it difficult to use such models for the on-line power system analysis. Even if some attributes can be assumed, it can potentially yield significant errors in the final calculation results.

A state estimator has been developed to prevent the impact of such errors on the optimization calculations and to improve their accuracy. Due to the application of a group of modules, some kind of a bridge has been obtained. In the developed prototype, the bridge consists of a connection between a real HV power system controlled by the SCADA system and the tool for optimization calculations. A simplified diagram of those relations is shown in Fig. 2.
The primary function of the state estimator is to provide a simplified error-free mathematical model for the on-line optimization. In order to determine an actual model, the state estimator is equipped with such modules as topology processor, observability test, estimation calculation, bad data detection and identification [3, 8]. Cooperation of those modules is illustrated by Fig. 3 .

The first module is responsible for retrieving measurement data from the SCADA system including analog measurements like voltage, active and reactive power flow. Switch status data (binary measurements) are used for the topology determination purposes. The topology processor algorithm consists of the following steps: a collection of the measured data and the static model data (impedance, energy source data, energy consumption data), determination of the topology (using binary measurements), matching the measurement data with the model elements. There are many various algorithms that can be applied to the topology processor. In the discussed project a simplified algorithm has been used.

At the final stage of the discussed process, a mathematical model of the power system is obtained. There is some probability that the obtained model can lack observability. This lack of observability can be caused by a few factors. A model can be considered as observable when the following condition is met

$$
\begin{gathered}
m \geq x \\
x=2 N-1
\end{gathered}
$$

where: $m$ - number of measurements, $x$ - number of state variables, $N$ - number of buses.

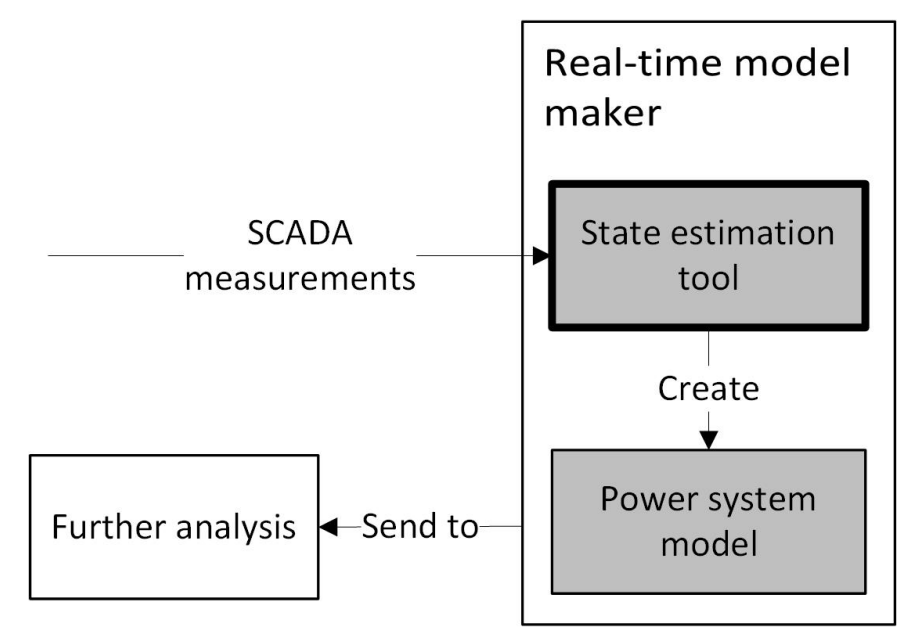

Figure 2 Data flow between the SCADA system and the optimization module 


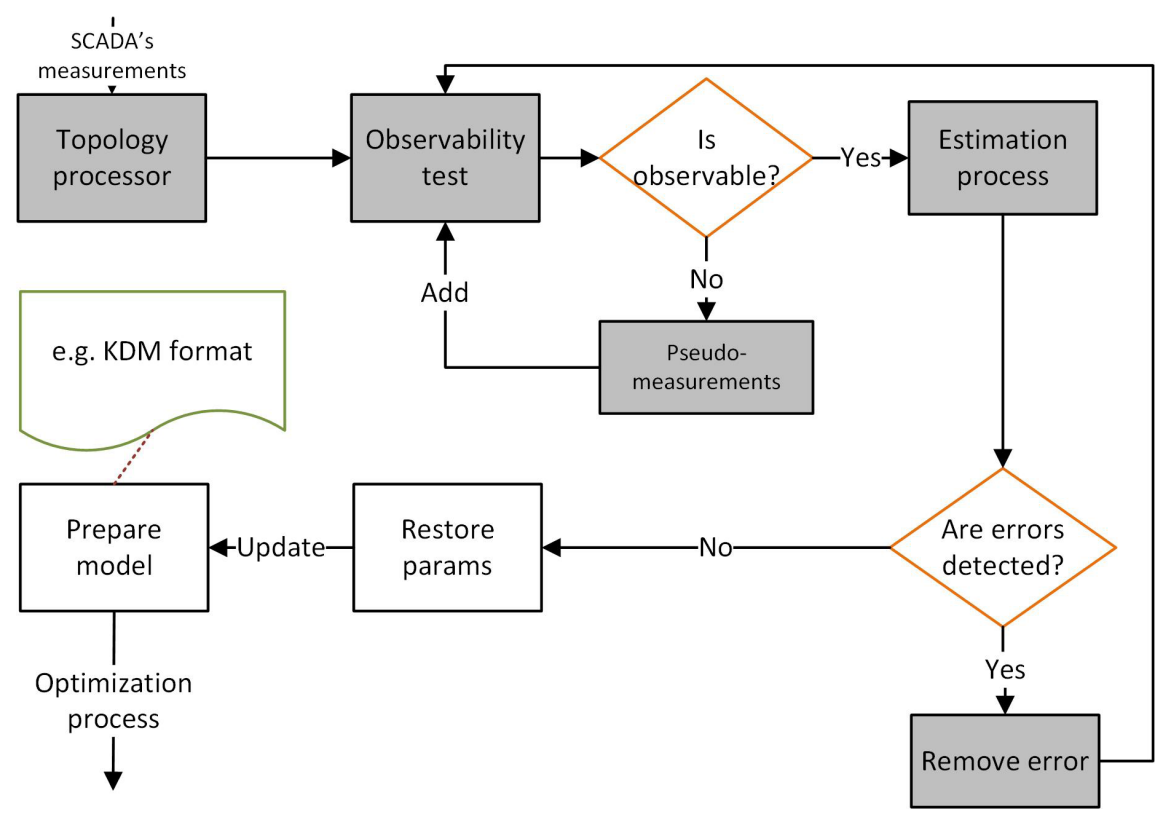

Figure 3 Real-time modeling of a power network system

It is not the only criterion. Prior to the state estimation calculation, the presence of observable islands, critical measurements, and unobservable branches has to be checked. In order to determine the mentioned data, an advanced algorithm has been applied [4]. The presented algorithm has many advantages. Owing to that method it is possible to check, which of the elements can be considered as observable, where are the critical measurements, does the model include observable islands and finally to establish whether the model is observable. If the observability test detects unobservable branches, the method can indicate areas of no measurement data, where pseudo-measurements can be used.

State estimation calculation is crucial for the model analysis. It is a module that determines the most probable state of the analyzed power system described by a voltage vector. It makes a basis for following calculations of the model parameters. In the discussed project, the Weighted Least Square (WLS) state estimation algorithm has been used [1]. For the estimation purposes, power injection, power flow, and voltage measurements have been used. Those measurements can be expressed as follows:

1.1. injection of active and reactive power at the bus $i$ :

$$
\begin{aligned}
& P_{i}=V_{i} \sum_{j \in N} V_{j}\left(G_{i j} \cos \Theta_{i j}+B_{i j} \sin \Theta_{i j}\right) \\
& Q_{i}=V_{i} \sum_{j \in N} V_{j}\left(G_{i j} \sin \Theta_{i j}-B_{i j} \cos \Theta_{i j}\right)
\end{aligned}
$$

1.2. active and reactive power flow from the bus $i$ to $j$ :

$P_{i j}=V_{i}^{2}\left(g_{s i}+g_{i j}\right)-V_{i} V_{j}\left(g_{i j} \cos \Theta_{i j}+b_{i j} \sin \Theta_{i j}\right)$

$Q_{i j}=-V_{i}^{2}\left(b_{s i}+b_{i j}\right)-V_{i} V_{j}\left(g_{i j} \sin \Theta_{i j}-b_{i j} \cos \Theta_{i j}\right)$

where: $V_{i}, \Theta_{i}$ is the voltage and phase angle at the bus $i$.

$\Theta_{i j}=\Theta_{i}-\Theta_{j}$.

$G_{i j}+j B_{i j}$ is the $i j$-th element of the complex bus admittance matrix.

$g_{i j}+j b_{i j}$ is the admittance of the series branch connecting buses $i$ and $j$.

$g_{s i}+j b_{s i}$ is the admittance of the shunt branch connected to the bus $i$.

Power system model includes $m$ measurements. Each of them can be encumbered with some measurement error:

$z=\left[\begin{array}{c}z_{1} \\ z_{2} \\ \vdots \\ z_{m}\end{array}\right]=\left[\begin{array}{c}h_{1}\left(x_{1}, x_{2}, \ldots, x_{n}\right) \\ h_{2}\left(x_{1}, x_{2}, \ldots, x_{n}\right) \\ \vdots \\ h_{m}\left(x_{1}, x_{2}, \ldots x_{n}\right)\end{array}\right]+\left[\begin{array}{c}e_{1} \\ e_{2} \\ \vdots \\ e_{m}\end{array}\right]=h(x)+e$

where: $z, z^{T}=\left[z_{1}, z_{2}, \ldots, z_{m}\right]$ is a measurement matrix, $h_{i}(x)$ is a nonlinear function relating the measurement $i$ to the state vector 
$\chi, x^{\mathrm{T}}=\left[x_{1}, x_{2}, \ldots, x_{n}\right]$ is the system state vector,

$e, e^{T}=\left[e_{1}, e_{2}, \ldots, e_{m}\right]$ is measurement error matrix.

All measurements are described by their standard deviation

$$
\mathbf{R}=\operatorname{diag}\left\{\sigma_{1}^{2}, \sigma_{2}^{2}, \ldots, \sigma_{m}^{2}\right\}
$$

Having the measurements described with equations, the WLS estimator can be used to find the function minimum

$$
\begin{gathered}
J(x)=\sum_{i=0}^{m} \frac{\left(z_{i}-h_{i}(x)\right)^{2}}{R_{i i}}= \\
=[z-h(x)]^{\mathrm{T}} R^{-1}[z-h(x)]=\text { min }
\end{gathered}
$$

The function minimum exists if

$$
g(x)=\frac{\partial J(x)}{\partial x}=-H^{\mathrm{T}}(x) R^{-1}[z-h(x)]=0
$$

where:

$$
H(x)=\left[\frac{\partial h(x)}{\partial x}\right]
$$

Expansion of the non-linear function $g(x)$ into its Taylor series around the state vector $x^{k}$ yields:

$$
g(x)=g\left(x^{k}\right)+G\left(x^{k}\right)\left(x-x^{k}\right)+\ldots=0
$$

where: $k$ is the iteration index and $G\left(x^{k}\right)$ is a gain matrix expressed as

$$
G\left(x^{k}\right)=\frac{\partial g\left(x^{k}\right)}{\partial x}=H^{\mathrm{T}}\left(x^{k}\right) R^{-1} H\left(x^{k}\right)
$$

It leads to an iterative solution as follows:

$$
x^{k+1}=x^{k}-\left[G\left(x^{k}\right)\right]^{-1} g\left(x^{k}\right)
$$

The complete equation is shown below

$$
\begin{gathered}
x^{k+1}=x^{k}+\left[H^{\mathrm{T}}\left(x^{k}\right) R^{-1} H\left(x^{k}\right)\right]^{-1} \\
H^{\mathrm{T}}\left(x^{k}\right) R^{-1}\left[z-h\left(x^{k}\right)\right] \\
x^{k+1}=x^{k}+\Delta x^{k+1}
\end{gathered}
$$

Voltage (state variable) vector is computed till the voltage increase gets lower than the arbitrarily set $\varepsilon$ value.

$$
\left|\Delta x^{k+1}\right| \leq \varepsilon
$$

At the next stage, the estimated values are treated as suspicious. This assumption is necessary because any of the estimated voltage values can appear to be a bad value following from a measurement encumbered with a gross error. Such errors have to be detected and eliminated from the computation process. There are many BDD/BDI algorithms. Each of them has its advantages and disadvantages. A method referred to as the "Largest Normalized Residual Test" has been applied because it is characterized by satisfactory error detection and efficient identification.

If the module $\mathrm{BDD} / \mathrm{BDI}$ does not detect any errors, the computed voltage vector is a solution that is the most adequate for the actual system state. This information is used to determine the model parameters (generations, loads, power losses) that have been removed in the computation process or do not exist at all. Next, the developed model is subdued to further analyses by the optimization module.

\section{OPTIMIZATION COMPUTATIONS}

A module that solves linear optimization tasks using a method of load flow tracing has been developed for the discussed tool. The algorithm combines the optimization method with the method of load flow tracing, which may seem a little futuristic but it enables sufficient clearance of the effects of exceeding the allowed transmission capacity.

The active power flow tracing method makes possible to control power generated from selected sources, and thereby to determine the impact of their generation on the loads in individual branches. Thus, it gets possible to identify those power plants, whose responsibility for the power flow in a selected line or transformer is the greatest (determination of coefficients indicating the share of power generated in the sources in the loading of selected branches in the grid). The method has been introduced to power engineering in the 1990s $[2,10]$.

The load-flow tracing method makes possible to identify the source that is the most responsible for the load in a given line. However, it is not de- 
cisive that once power generated in this source gets reduced, the power flows change so that the line load gets relieved efficiently. It is possible that a reverse effect can occur and namely that the power flow change can bring about an increase of the load in the considered line. Power loss resulting from a reduced generation in a given power plant can be compensated by the power that inflows from other sources or from a balancing node, which eventually results in a deterioration of the power flow condition. Another effect of such a power output reduction can be an overload of another branch (or other branches) that has not been overloaded before. Thus, if the line load relief is to be effective, the flow tracing method has to be accordingly modified. The presented article discusses a modified version of the method. Its primary objective is to get an adequate response (of a grid operator and eventually of automatic power controls) to the exceeded load limits in grid branches of the monitored area. The method is based on share ratios calculated by the power flow tracing method. Those coefficients have been assumed to be stable within a specific limited range of changes in the active power generated in the sources that are the most responsible for the load in a given branch.

Power flows between the branches i-l, s-t and $\mathrm{m}-\mathrm{n}$ in their overload condition can be represented by the following dependences $[9,10]$ :

$$
\begin{aligned}
& P_{i l}=u_{i l, 1} \cdot P_{\mathrm{G} 1}+u_{i l, 2} \cdot P_{\mathrm{G} 2}+\ldots+u_{i l, N_{\mathrm{G}}} \cdot P_{\mathrm{G} N_{\mathrm{G}}} \\
& P_{s t}=u_{\mathrm{st}, 1} \cdot P_{\mathrm{G} 1}+u_{\mathrm{st}, 2} \cdot P_{\mathrm{G} 2}+\ldots+u_{\mathrm{st}, N_{\mathrm{G}}} \cdot P_{\mathrm{G} N_{\mathrm{G}}} \\
& P_{m n}=u_{\mathrm{mn}, 1} \cdot P_{\mathrm{G} 1}+u_{\mathrm{mn}, 2} \cdot P_{\mathrm{G} 2}+\ldots+u_{\mathrm{mn}, N_{\mathrm{G}}} \cdot P_{\mathrm{G} N_{\mathrm{G}}}
\end{aligned}
$$

where: $u_{i l, \mathrm{k}}-$ coefficient that determines loading of a branch $i-l$ from the source located in the node $\mathrm{k}$ (share ratio), $P_{G k}-$ active power generated in the node $k$, $N_{G}$ - number of sources.

To eliminate the overloads, it is necessary to reduce power in the sources by the value of $\Delta P$. Thus, for the no-overload condition the above equations can be written as follows:

$$
\begin{gathered}
P_{i l}^{\prime}=u_{i l, 1} \cdot\left(P_{\mathrm{G} 1}-\Delta P_{\mathrm{G} 1}\right)+\ldots \\
+u_{i l, N_{\mathrm{G}}} \cdot\left(P_{\mathrm{G} N_{\mathrm{G}}}-\Delta P_{\mathrm{G} N_{\mathrm{G}}}\right)
\end{gathered}
$$

$$
\begin{gathered}
P_{s t}^{\prime}=u_{\mathrm{st}, 1} \cdot\left(P_{\mathrm{G} 1}-\Delta P_{\mathrm{G} 1}\right)+\ldots \\
+u_{\mathrm{st}, N_{\mathrm{G}}} \cdot\left(P_{\mathrm{G} N_{\mathrm{G}}}-\Delta P_{\mathrm{G} N_{\mathrm{G}}}\right) \\
P_{m n}^{\prime}=u_{\mathrm{mn}, 1} \cdot\left(P_{\mathrm{G} 1}-\Delta P_{\mathrm{G} 1}\right)+\ldots \\
+u_{\mathrm{mn}, N_{\mathrm{G}}} \cdot\left(P_{\mathrm{G} N_{\mathrm{G}}}-\Delta P_{\mathrm{G} N_{\mathrm{G}}}\right)
\end{gathered}
$$

The no-overload condition is met when the following dependencies occur:

$$
\begin{gathered}
P_{i l}^{\prime} \leq P_{i l(\max )} \\
P_{s t}^{\prime} \leq P_{s t(\max )} \\
P_{m n}^{\prime} \leq P_{m n(\max )}
\end{gathered}
$$

Total power output reduction is given by the formula:

$$
\Delta P=\Delta P_{\mathrm{G} 1}+\Delta P_{\mathrm{G} 2}+\ldots+\Delta P_{\mathrm{G} N_{G}}
$$

The analyzed issue can be considered as a nonlinear optimization task with equality and inequality constraints, where the objective function assumes the following form 8 :

$$
F_{\mathrm{c}}=\min \left(\Delta P_{\mathrm{G} 1}+\Delta P_{\mathrm{G} 2}+\ldots+\Delta P_{\mathrm{G} N_{G}}\right)
$$

It should be noted that in the process of changes in the power outputs of individual sources their ratios of power share in the load flow of a given branch can change as well. The core idea of the flow tracing method is the use of power values obtained from a non-linear analysis of the system, hence using its results for the above described linear optimization process involves some simplifications, subsequently compensated in successive iterations.

Tests have been performed for the testing grid CIGRE. It is a grid that consists of 12 generators, 17 nodes, 19 lines, and two autotransformers. A diagram of the grid is shown in Fig. 4. Conventional sources are marked in yellow, and wind farms in red.

The primary state of this grid is characterized by the occurrence of overloads in five branches - four lines and a transformer (Table 1), which is illustrated by the percent load rates of individual branches. The total power output of the wind farms amounts to $750 \mathrm{MW}$. Optimization 


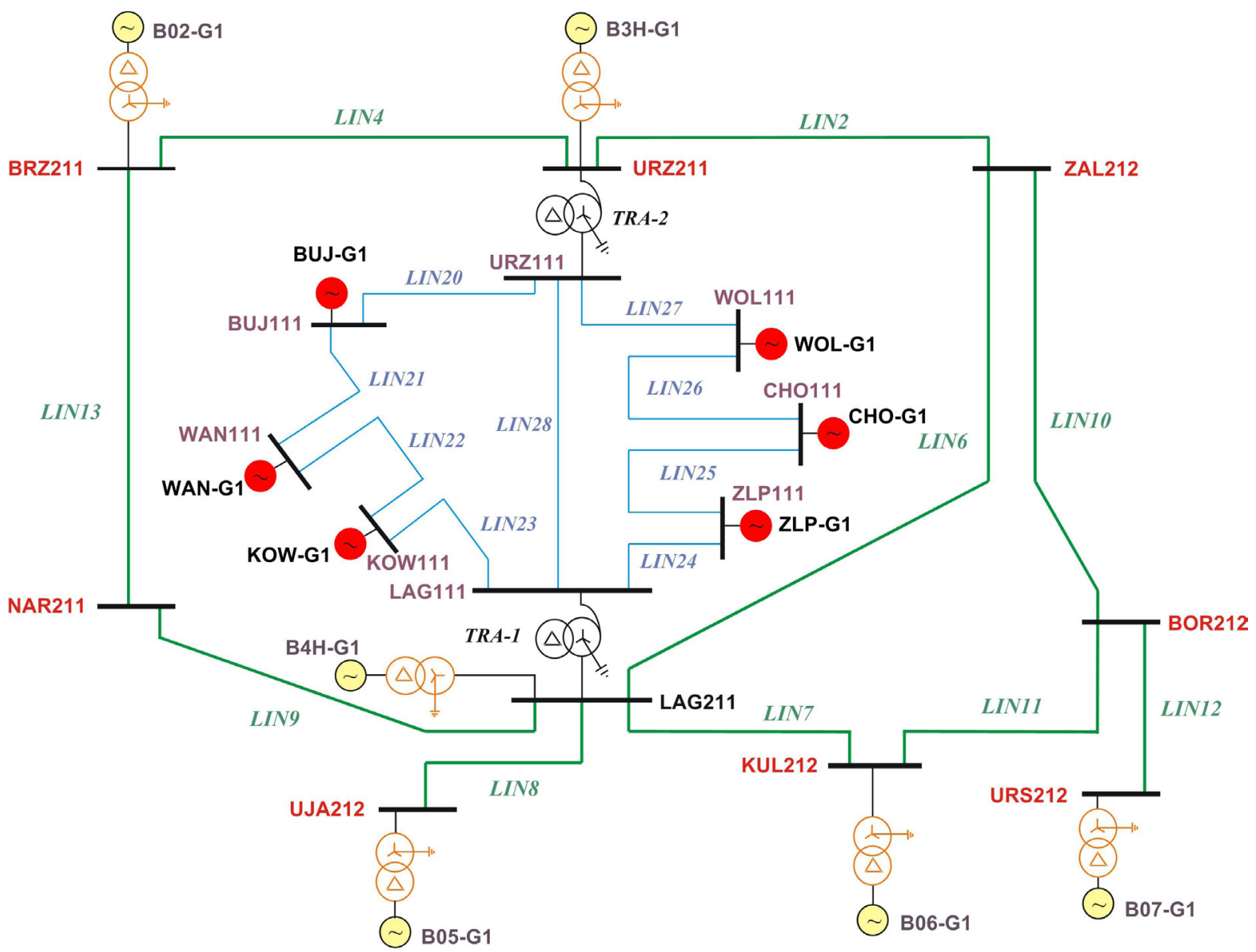

Fig. 4. CIGRE test grid diagram

Table 1. Overloaded Elements

\begin{tabular}{|c|c|c|c|c|c|c|}
\hline \multirow[b]{2}{*}{ No. } & \multirow[b]{2}{*}{ Branch code } & \multirow[b]{2}{*}{ Start node } & \multirow[b]{2}{*}{ End node } & \multirow{2}{*}{$\begin{array}{l}\ln / \mathrm{Sn} \\
(\mathrm{A} / \mathrm{MVA})\end{array}$} & $\begin{array}{c}\text { Before } \\
\text { optimization }\end{array}$ & $\begin{array}{c}\text { After } \\
\text { optimization }\end{array}$ \\
\hline & & & & & \multicolumn{2}{|c|}{$\begin{array}{c}\mathrm{I} / \mathrm{In} \\
(\mathrm{S} / \mathrm{Sn}) \\
\%\end{array}$} \\
\hline 1 & LIN20 & URZ111 & BUJ111 & 205 & 121 & 91 \\
\hline 2 & LIN23 & KOW111 & LAG111 & 205 & 214 & 100 \\
\hline 3 & LIN24 & LAG111 & ZLP111 & 205 & 194 & 94 \\
\hline 4 & LIN27 & WOL111 & URZ111 & 320 & 183 & 97 \\
\hline 5 & TRA-2 & URZ211 & URZ111 & 160 & 106 & 70 \\
\hline
\end{tabular}

calculations have been performed for the abovedescribed grid state. No-overload grid condition has been obtained in one iteration, which proves high efficiency of the method.

The total power output of the wind farms has been reduced by the value of $156,5 \mathrm{MW}$. It is the smallest possible reduction that brings about effective relieving of overloaded elements. Output power loss in the wind farms has been compensated by conventional sources to maintain the grid power balance which caused the increase of thermal generation (Table 2). Assuming that all conventional power plants had the same cost characteristics written as follows [5]:

$$
C_{i}: P_{g i}+0.025 \cdot P_{g i}{ }^{2}
$$

moreover, in the base state had been operating at 1 p.u./h cost. Thus the costs after the line load reducing action are presented in Table 2.

The modified load flow tracing method combines the advantages of non-linear and linear approaches Considering its advantageous characteristics such as low complexity, high operation rate, and accuracy; it can be applied on-line. 
Table 2. Optimized active power settings and costs

\begin{tabular}{|c|c|c|c|c|c|}
\hline No. & Source type & $\begin{array}{c}\text { Pg, MW } \\
\text { base state }\end{array}$ & $\begin{array}{c}\text { Pg, MW } \\
\text { optimal case }\end{array}$ & $\begin{array}{c}\text { Cost, p.u./h } \\
\text { optimal case costs }\end{array}$ & Code \\
\hline 1 & FW & 115 & 101,5 & & BUJ-G1 \\
\hline 2 & FW & 100 & 100 & & WAN-G1 \\
\hline 3 & FW & 125 & 79 & \multirow{2}{*}{ KOW-G1 } \\
\hline 4 & FW & 150 & 121 & & WOL-G1 \\
\hline 5 & FW & 120 & 54 & & CHO-G1 \\
\hline 6 & FW & 140 & 138 & & ZLP-G1 \\
\hline 7 & Conventional & 0 & 0 & 1.409 & B02-G1 \\
\hline 8 & Conventional & 169 & 204 & 1.420 & B3H-G1 \\
\hline 9 & Conventional & 139 & 169 & 1.387 & B07-G1 \\
\hline 10 & Conventional & 179 & 214 & 1.403 & B05-G1 \\
\hline 11 & Conventional & 169 & 203,5 & 1.203 & B4H-G1 \\
\hline 12 & Conventional & 199 & 220 & & \\
\hline
\end{tabular}

\section{LABORATORY MODEL OF THE POWER SYSTEM STATE ESTIMATION AND OPTIMIZATION}

The presented tool for the power system state estimation has been equipped with a power system simulator module. Simulator and estimator modules operate in a closed loop, which makes possible to analyze their performance in normal operating conditions. The power system simulator is a computer equipped with a power flow software that generates responses to new conditions in the simulated grid based on control signals sent from the estimator.
A laboratory model (Fig. 5) has been developed to enable a full analysis of the phenomena that occur during the computation process. The model consists of:

- a computer with software to simulate the operation of a real power system and power flows in the grid,

- a PC with the estimation and optimization software,

- data hub with dedicated SCADA for power systems,

- Ethernet.

The control system operation has been shown in Fig. 6. At the beginning (like in real systems)

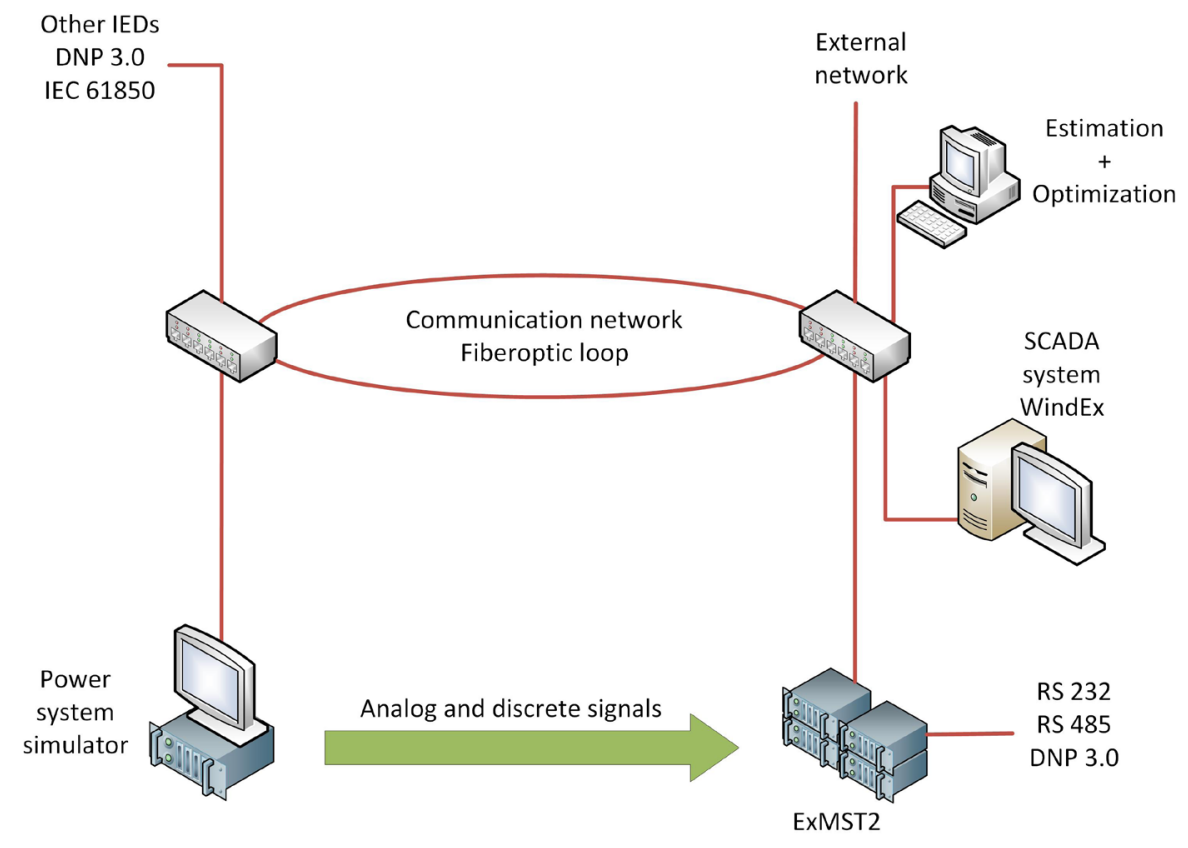

Fig. 5. Laboratory model of the optimal control system for wind farms 


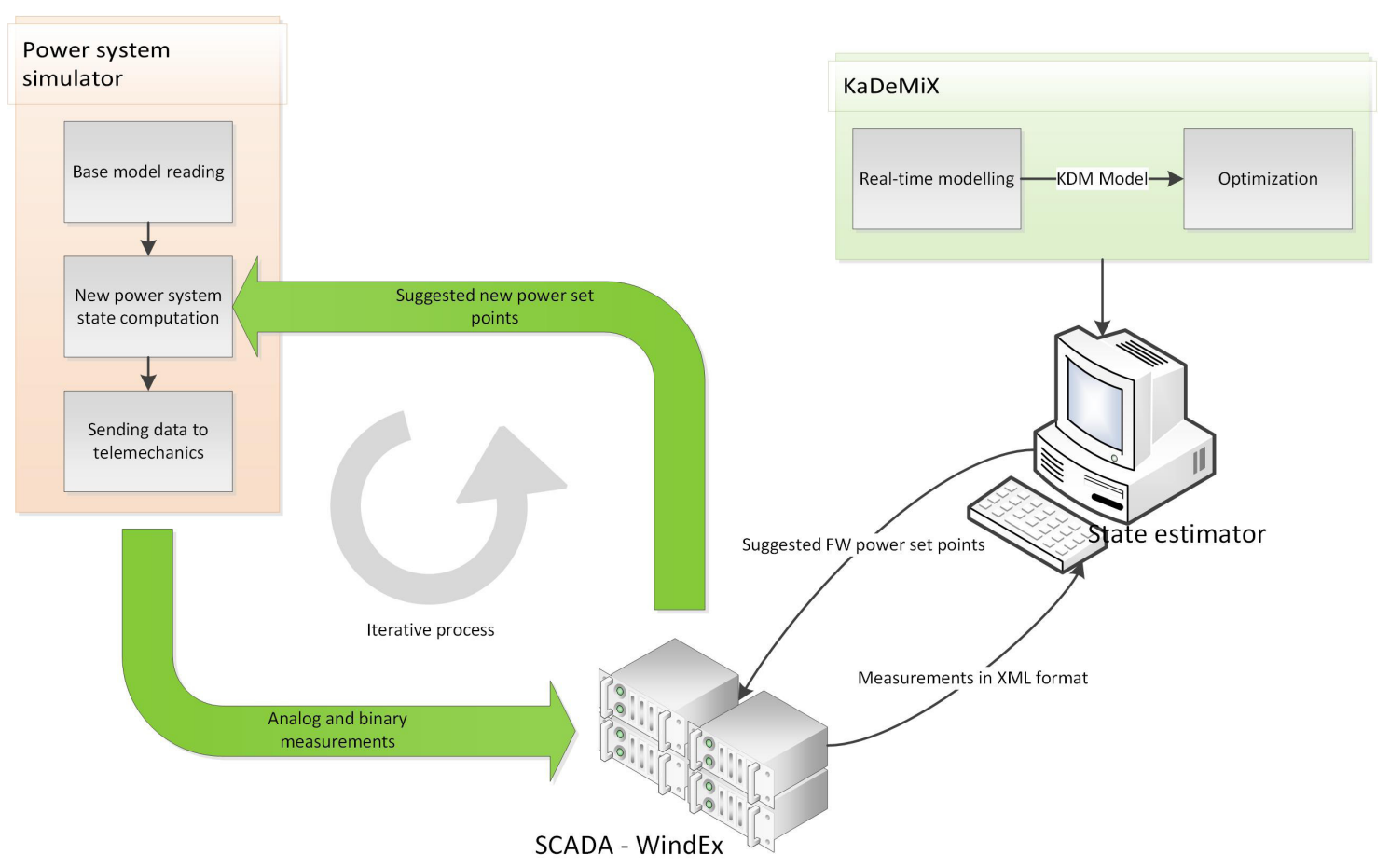

Fig. 6. Closed loop operation of the optimal wind farm control in the laboratory model

starting conditions for the simulation are set. Next, various bus loads are randomly changed to obtain overloading of power lines. Grid information (in the form of measurement data) is transmitted via Ethernet or fiber-optic connections to the data hub ExMST2. The obtained measurement data are currently analyzed and shown in the SCADA system. In a specified time interval, the power system state estimator module sends a measurement request to the SCADA system. On that basis, the estimator collects a set of grid measurement data and proceeds with the grid estimation procedure. Once the most likely power system state is determined, the estimator module sends the accurate grid model to the optimization module.

The optimization module calculates optimal settings for generating units (wind farms), to meet the actual power system balance and to reduce overloading of transmission power lines. The new determined settings for wind farms and other generating units are sent to the power system simulator. Optimal generation settings are treated as commands to modify power output of generating units. In the case of wind farms, it is a command to maintain or to reduce the actual generation. In the case of other generation units like thermal plants, three commands are possible: maintain, reduce or increase the actual generation. Next, the settings are sent to the simulator, where power flow calculations are performed followed by the determination of the new system state. The discussed laboratory power system control operates in a closed loop at a set time interval, and it can be stopped by the user.

\section{CONCLUSIONS}

In Poland, the presented optimal control system is an innovative and unique solution. Owing to the combined application of estimation and optimization modules the proposed optimal wind farm control system offers a higher quality of the power grid analysis than the previously used procedures. The system can be used to support decisions of the network operator. Implementation of such a system offers considerable economic benefits (lower energy losses, higher savings) and supports the development of renewable energy sources.

\section{Acknowledgements}

The authors would like to emphasize that the presented system has been developed within the framework of the research project N R01 002106 "A system of optimal wind farm power control in the conditions of limited transmission capacity of a power network system" $[6,7]$. 


\section{REFERENCES}

1. Abur A., Exposito A., Power System State Estimation. Theory and Implementation, Marcel Dekker, 2004.

2. Białek J.W., Tracing the flow of electricity, IEE Proc.-Gener. Transm. Distrib., July 1996, Vol. 143, 313-320.

3. Bose A., Clements K., Real-Time Modeling of Power Networks, IEEE Transactions on Power Systems. Vol. 75, No. 12, December 1987, 1607-1622.

4. Castillo E., Conejo A., Pruneda R., Observability Analysis in State Estimation - A Unified Numerical Approach, IEEE Transactions on Power Systems Vol. 21, No. 2, May 2006.

5. Crow M. L., Computational Methods for Electric Power Systems, CRC Press Taylor \& Francis Group, Boca Raton, FL, 2010, pp. 223.

6. Kacejko P., Wydra M, Rzepecki A., Pijarski P., Jędrychowksi R., Adamek S., Miller P., Wancerz M., A system of optimal wind farm power control in the conditions of limited transmission capacity of a power network system. Final report from research project N R01 002106 funded by National Centre for Research and Development.

7. Kacejko P., Wydra M., Jedrychowski R., Optimal control of wind farm group using the WindEx system and external computing modules, Zeszyty Naukowe Wydziału Elektrotechniki i Automatyki Politechniki Gdańskiej, APE'13, Gdańsk 2013.

8. Monticelli A., Electric Power system State Estimation, IEEE Transactions on Power Systems. Vol. 88, NO. 2, February 2000, 262-282.

9. Pijarski P., Dynamic Fitting of Generation Level to Transmission Capacity of Overhead Lines, doctoral thesis, Lublin University of Technology 2011.

10. Ziemianek S., Mathematical models of transmission loss allocation by active and reactive power flow tracing methods, Warsaw University of Technology, Prace Naukowe Elektryka, Vol. 127, Oficyna Wydawnicza Politechniki Warszawskiej, Warsaw 2003. 